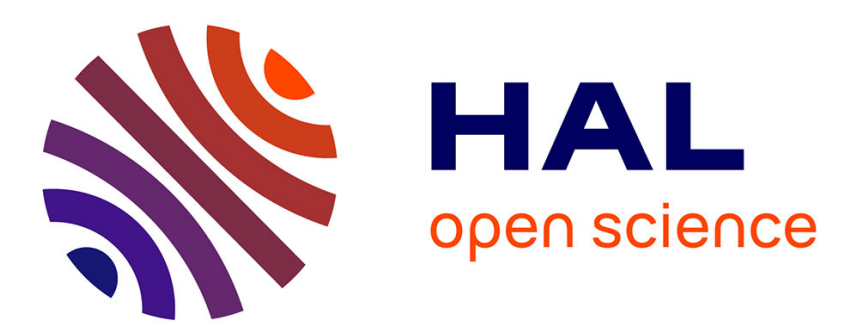

\title{
Characterization of materials and their interfaces in a direct bonded copper substrate for power electronics applications
}

\author{
Aymen Ben Kabaar, Cyril Buttay, Olivier Dezellus, R Estevez, Anthony \\ Gravouil, Laurent Gremillard
}

\section{To cite this version:}

Aymen Ben Kabaar, Cyril Buttay, Olivier Dezellus, R Estevez, Anthony Gravouil, et al.. Characterization of materials and their interfaces in a direct bonded copper substrate for power electronics applications. Microelectronics Reliability, 2017, 10.1016/j.microrel.2017.06.001 . hal-01541230

\author{
HAL Id: hal-01541230 \\ https://hal.science/hal-01541230
}

Submitted on 18 Jun 2017

HAL is a multi-disciplinary open access archive for the deposit and dissemination of scientific research documents, whether they are published or not. The documents may come from teaching and research institutions in France or abroad, or from public or private research centers.
L'archive ouverte pluridisciplinaire HAL, est destinée au dépôt et à la diffusion de documents scientifiques de niveau recherche, publiés ou non, émanant des établissements d'enseignement et de recherche français ou étrangers, des laboratoires publics ou privés. 


\title{
Characterization of Materials and Their Interfaces in a Direct Bonded Copper Substrate for Power Electronics Applications
}

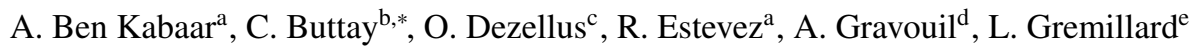 \\ ${ }^{a}$ SIMaP, UMR 5266, CNRS, Grenoble-INP, UJF, France \\ ${ }^{b}$ Univ Lyon, INSA-Lyon, CNRS, Laboratoire Ampére UMR 5005, F-69621, LYON, France \\ ${ }^{c}$ Univ Lyon, Univ Lyon 1, CNRS, LMI, UMR 5615, F-69622, LYON, France \\ ${ }^{d}$ Univ Lyon, INSA-Lyon, CNRS, LaMCoS, UMR 5259, F-69621, LYON, France \\ ${ }^{e}$ Univ Lyon, INSA-Lyon, CNRS, MATEIS Laboratory, UMR 5510, F-69621, LYON, France
}

\begin{abstract}
Direct Bonded Copper (DBC) are produced by high temperature $\left(>1000{ }^{\circ} \mathrm{C}\right)$ bonding between copper and a ceramic (usually alumina). They are commonly used in power electronics. However, their reliability when exposed to thermal cycling is still an issue, that could be addressed by advanced numerical simulations. This paper describes the identification of the parameters for a numerical model that uses finite elements with cohesive zones. This identification is based on careful mechanical characterization of all components of the DBC (ceramic, copper and interface) using an innovative approach based on image correlation.
\end{abstract}

\section{Introduction}

Direct-Bonded-Copper (DBC) substrates are commonly used in power electronics, because they both offer good thermal conductivity ( 24 to $180 \mathrm{~W} / \mathrm{mK}$ ) and suitable dielectric strength $(\approx 20000 \mathrm{~V} / \mathrm{mm}$ ) [1]. They are formed by attaching copper layers on both sides of a ceramic sheet $\left(\mathrm{Al}_{2} \mathrm{O}_{3}, \mathrm{AlN}\right.$, or in some cases $\mathrm{Si}_{3} \mathrm{~N}_{4}$ ).

Direct-bonding methods rely on the reaction between some metals and some gaseous atmospheres to form a film of eutectic liquid [2]. In particular, this can be applied to copper and oxygen (eutectic temperature $1065{ }^{\circ} \mathrm{C}$ at 1.7 at\% $\mathrm{O}$ ), to bond copper to ceramics, as $\mathrm{Cu}_{2} \mathrm{O}$ can wet $\mathrm{Al}_{2} \mathrm{O}_{3}$. The oxidation of copper can be performed at the time of assembly (12 min at $1072{ }^{\circ} \mathrm{C}$, with a partial pressure of oxygen of more than $1.5 \times 10^{-3}$ mbar [2]). Alternatively, the copper can be pre-oxidized separately [3], and then assembled to the ceramic. For a 3-10 $\mu$ m-thick oxide layer, the DBC structure exhibits a very good bond (140 MPa shear strength [3]). Details on the assembly process are given in [4] for $\mathrm{Al}_{2} \mathrm{O}_{3}$ ceramic, while [5] describes a variant using $\mathrm{AlN}$, which also requires an oxidation of the ceramic to form a superficial $\mathrm{Al}_{2} \mathrm{O}_{3}$ layer. From an application point-of-view, several implementations, including vias through the ceramic or hermetic packages, are presented in [6].

A major issue with DBC substrates, despite the quality of their metal-to-ceramic bond, is their weakness regarding ther-

\footnotetext{
* Corresponding author

Email addresses: Aymen.Ben-Kaabar@insa-lyon.fr (A. Ben Kabaar), cyril.buttay@insa-lyon.fr (C. Buttay),

olivier.dezellus@univ-lyon1.fr (O. Dezellus),

rafael.estevez@simap.grenoble-inp.fr (R. Estevez),

antony.gravouil@insa-lyon.fr (A. Gravouil),

laurent.gremillard@insa-lyon.fr (L. Gremillard)
}

mal cycling: the mismatch in Coefficients of Thermal Expansion (CTE) between copper and $\mathrm{Al}_{2} \mathrm{O}_{3}$ (17.5 and $6.8 \mathrm{ppm} / \mathrm{K}$ resp. [7]) generates thermo-mechanical stresses which can eventually yield to failure. In some cases [8], fewer than 50 cycles are necessary for a DBC to fail. Thermal cycling is a very common stress in power electronics, especially for transportation applications, where components are expected to survive thousands of cycles, with temperature amplitude exceeding $200{ }^{\circ} \mathrm{C}$ [9]. Test standards for power electronics describe several temperature cycling conditions the power modules must pass [7], but reliability remains one of the factors that limits the development of power electronics [10].

In the case of DBC substrates, many solutions were investigated to increase robustness to thermal cycling. For example, [11] demonstrates that thinner copper layers results in stronger substrates. An optimization method is presented in [12], and also results in a smaller ratio between copper and ceramic thicknesses. However, the resulting structure is not tested experimentally. The edges of the copper tracks are weak points in DBCs, because they concentrate mechanical stress [11]. Therefore, some solutions focus on reducing this concentration: "dimples" [6] are a series of small holes etched near the edges of the copper tracks to reduce their equivalent thickness (tapered edges). They are shown to offer a 10-fold improvement in the number of thermal cycles before failure [6,11]. A similar approach is to actually reduce the thickness of the periphery of the copper layer, with a "staircase" structure [13].

Numerical simulation is required to analyze the stress distribution in the DBC structure, so it can be improved further. This requires accurate models to describe the behavior of the copper, the ceramic and their interface. In particular [14] showed that the hardening of the copper (during thermal cycling) plays a very important role. In [15], it is shown that submitting the $\mathrm{DBC}$ to a few wide thermal cycles actually makes it more ro- 


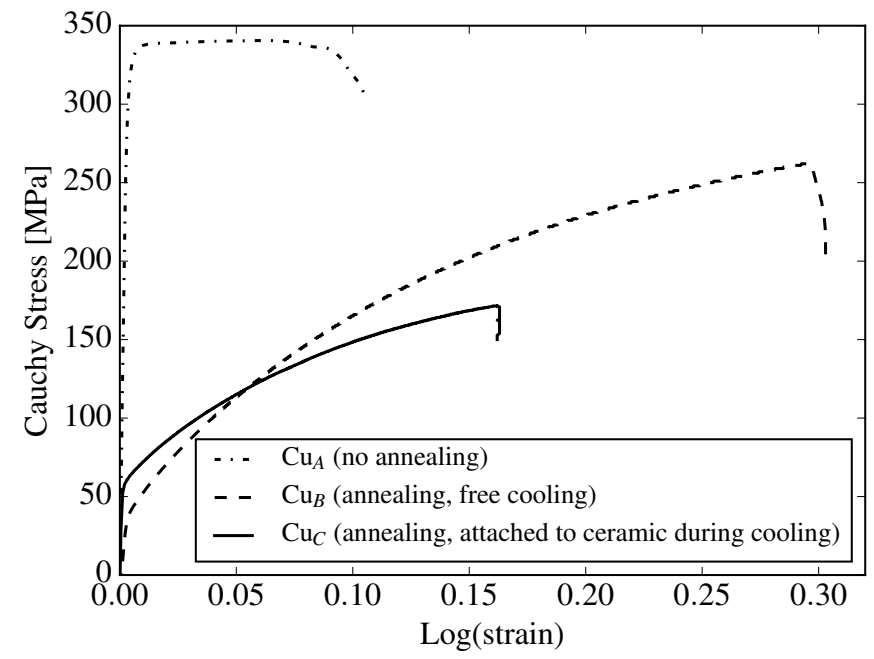

Figure 1: Stress-strain graph for the three copper grades.

bust to further (narrower) cycling. Numerical models can help analyzing this counter-intuitive example. This requires accurate models for the various elements of the $\mathrm{DBC}$, which is the point of the present article

The copper layers are annealed during the assembly process of the DBC, and then cooled-down under mechanical stress (once attached to the ceramic). As a consequence, their mechanical properties are very different from those of the original copper sheet. This is presented in the first section of this article. In the second section, two varieties of bare ceramic sheets (alumina and zirconia-toughened alumina) are characterized. Finally, the behavior of the metal/ceramic interface is investigated in the third section, using 4-points bending and a cohesive model to represent the mechanical response of the interface. This results in a set of parameters that can be used for accurate modeling and prediction of the integrity of the entire DBC structure.

\section{Characterization of the copper layer}

DBC substrates have thick copper layers (usually ranging from 127 to $500 \mu \mathrm{m}$ [16]). A thick copper layer is desirable to carry high electric currents (low electrical resistance). In the following, we used copper layers (Rogers-Curamik, $300 \mu \mathrm{m}$ thick) in the following states:

- $\mathrm{Cu}_{A}$ : The copper sheets, before any DBC-related processing

- $\mathrm{Cu}_{B}$ : The same sheets, after annealing (these sheets have gone through the full DBC process, but were not attached to a ceramic, so no external mechanical stress was applied during cooling down)

- $\mathrm{Cu}_{C}$ : These sheets experienced the full DBC process, and were attached to a ceramic; as a consequence, they experienced both annealing and external stress during cooling down. The ceramic (here $\mathrm{AlN}$, as $\mathrm{Al}_{2} \mathrm{O}_{3}$ is chemically

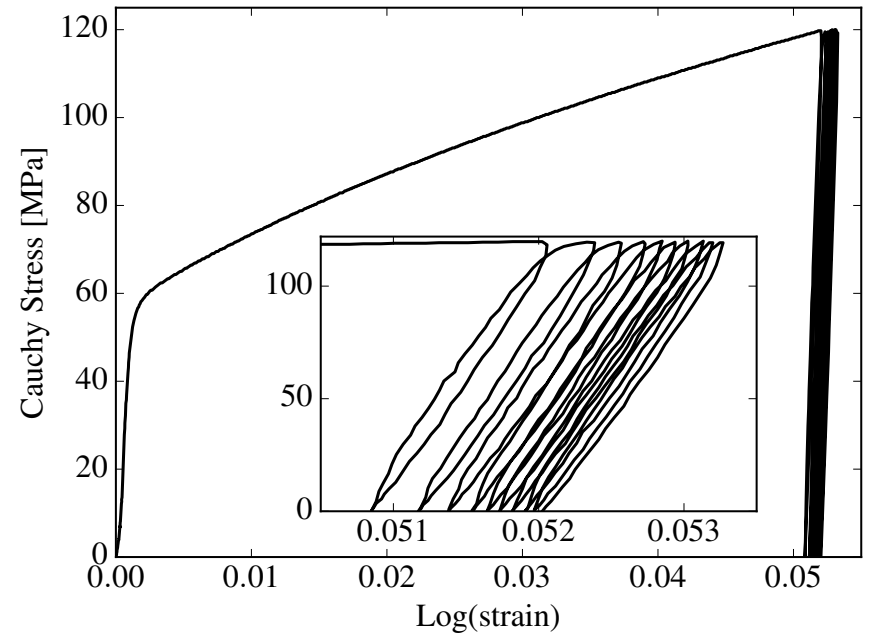

Figure 2: Example of stress-strain curve measured for $120 \mathrm{MPa}$ repetitive loading on a specimen of $\mathrm{Cu}_{C}$.

inert) was then etched away after assembly by dipping the substrate in a $\mathrm{NaOH}$ bath at $90{ }^{\circ} \mathrm{C}$ for $12 \mathrm{~h}$. Only the copper layer remained after this chemical attack.

It is worth noting that the actual annealing parameters were not disclosed by Rogers-Curamik. However, from the literature presented in section 1 (refs $[2,3,4,5,6]$ ), one can estimate that $\mathrm{Cu}_{B}$ and $\mathrm{Cu}_{C}$ underwent a maximum temperature of $\approx 1070{ }^{\circ} \mathrm{C}$.

Dumbell tensile-test specimens (test area $20 \mathrm{~mm}$ long, $14 \times 0.3 \mathrm{~mm}^{2}$ cross section) were cut in each copper sheet using electrical-discharge machining. These specimens were submitted to uni-axial tensile characterization (identification of their elastic and plastic properties), or to cyclic tensile loading (to investigate the kinematic hardening behavior).

For the uni-axial tests (equipment: Zwick / Roell model 1455 with a $20 \mathrm{kN}$ load cell, $1 \mu \mathrm{m} / \mathrm{s}$ fixed displacement), digital image correlation was used for the measurement of the strain in the axial and transverse directions. The mechanical response in terms of Cauchy stress vs. strain is then derived [17]. The graph in figure 1 shows a clear difference between copper grades: in particular, the high-temperature annealing $\left(\mathrm{Cu}_{B}\right.$ and $\left.\mathrm{Cu}_{C}\right)$ dramatically decreases the yield stress compared to the nonannealed samples $\left(\mathrm{Cu}_{A}\right)$. Even the mechanical stress applied during cooling-down has a visible effect, with a higher yield point for $\mathrm{Cu}_{C}$ than for $\mathrm{Cu}_{B}$. As a consequence, the identification of the model parameters should be performed on $\mathrm{Cu}_{C}$, which is representative of the actual state of the copper in the DBC assembly.

Using the uni-axial test data for $\mathrm{Cu}_{C}$, the Young's modulus $E$ is found to be $127 \mathrm{GPa}( \pm 1 \mathrm{GPa})$, the Poisson's ratio $v=0.33$, and the yield stress $\sigma_{y}=60 \mathrm{MPa}( \pm 5 \mathrm{MPa})$.

For the identification of the plastic response, specimens of $\mathrm{Cu}_{C}$ were then tested using repetitive loading. Only tensile stress was applied, as such thin specimens would buckle under compressive stress. A maximum loading stress of $\sigma_{\text {max }}=120 \mathrm{MPa}$ is used, to observe the effect of the kinematic hardening. Ratcheting is clearly visible in Fig. 2, with an in- 
Table 1: Elasto-plastic parameters for $C u_{C}$ copper. $\mathrm{E}$ is the Young's modulus, $v$ the Poisson's ratio, $\sigma_{y}$ the yield stress. $\mathrm{C}$ and $\gamma$ are two parameters used in the kinematic hardening model [18].

\begin{tabular}{ccccc}
$\mathrm{E}[\mathrm{GPa}]$ & $v$ & $\sigma_{y}$ & $\mathrm{C}[\mathrm{MPa}]$ & $\gamma$ \\
\hline 127 & 0,33 & 60 & 1677 & 14,6 \\
\hline
\end{tabular}

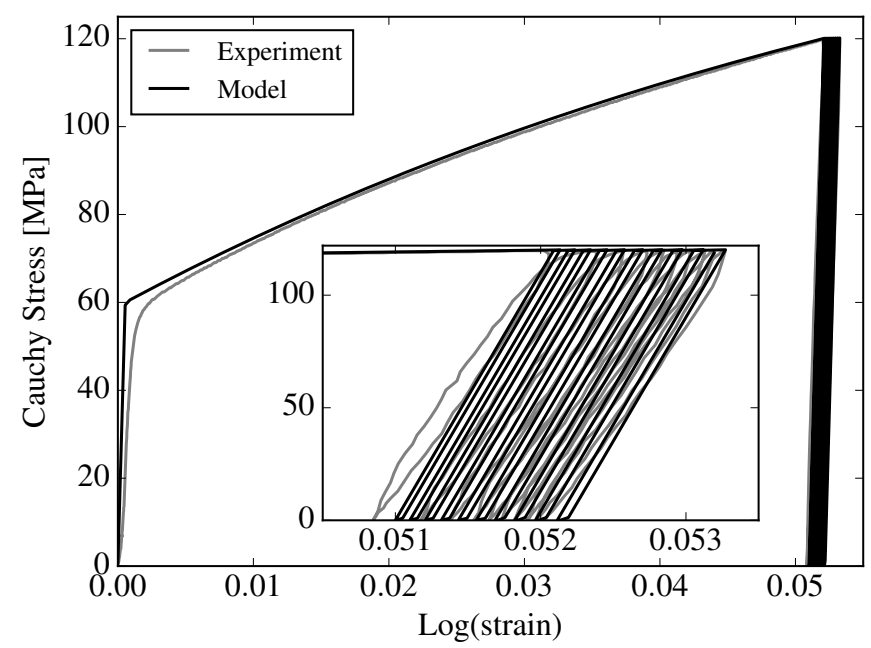

Figure 3: Comparison of the model response with the tensile test of a $\mathrm{Cu}_{C}$ specimen from Fig. 2.

crease of the plastic strain for each loading cycle, which tends to stabilize for a large number of cycles.

A kinematic hardening model (Armstrong-Frederick, [18]) is used to describe the plastic response of $\mathrm{Cu}$, and in particular the ratcheting observed during the repeated tensions from zero to a maximum stress. Two parameters need to be identified, $C$ and $\gamma$ in the Armstrong Frederiks formulation.

These are found from a least square minimization procedure to capture both the monotonic response and the ratcheting under repeated loadings. A kinematic formulation is necessary to accurately capture the copper response during loading cycles, for instance.

Tab. 1 presents the value of the parameters after identification, and Fig. 3 shows the comparison between this model and the measurement from Fig. 2.

\section{Characterization of the ceramic layer}

Two grades of alumina $\left(\mathrm{Al}_{2} \mathrm{O}_{3}\right)$ ceramic commonly used in DBC assemblies are investigated here, to characterize their statistical fracture: the standard grade (with an average grain size of $3 \mu \mathrm{m}$ ), and a zirconia- $\mathrm{Al}_{2} \mathrm{O}_{3}$ composite with yttrium doping $\left(9 \% \mathrm{Zr}, 91 \% \mathrm{Al}_{2} \mathrm{O}_{3}\right)$. This latter grade has a higher resistance to cracking. Both materials were supplied by Rogers-Curamik as thin plates $\left(635 \mu\right.$ m-thick for $\mathrm{Al}_{2} \mathrm{O}_{3}, 250 \mu$ m-thick for the $\left.\mathrm{Zr}-\mathrm{Al}_{2} \mathrm{O}_{3}\right)$.

\subsection{3-point Bending tests}

4-mm wide specimens (30 for $\mathrm{Al}_{2} \mathrm{O}_{3}$, and 27 for $\mathrm{Zr}-\mathrm{Al}_{2} \mathrm{O}_{3}$ ) are cut in the ceramic sheets using a wafer saw (Disco DAD

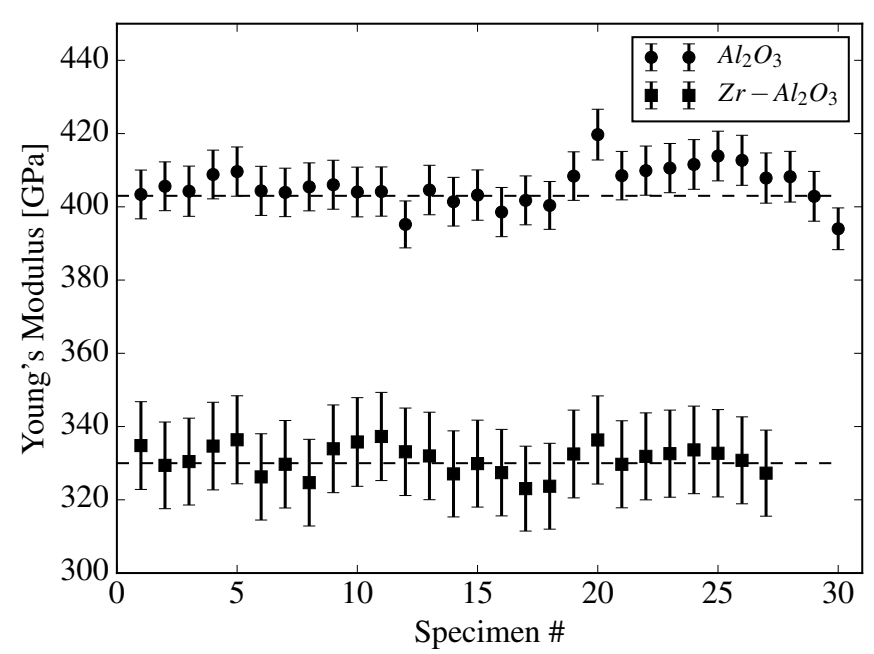

Figure 4: Young's modulus calculated for each specimen tested.

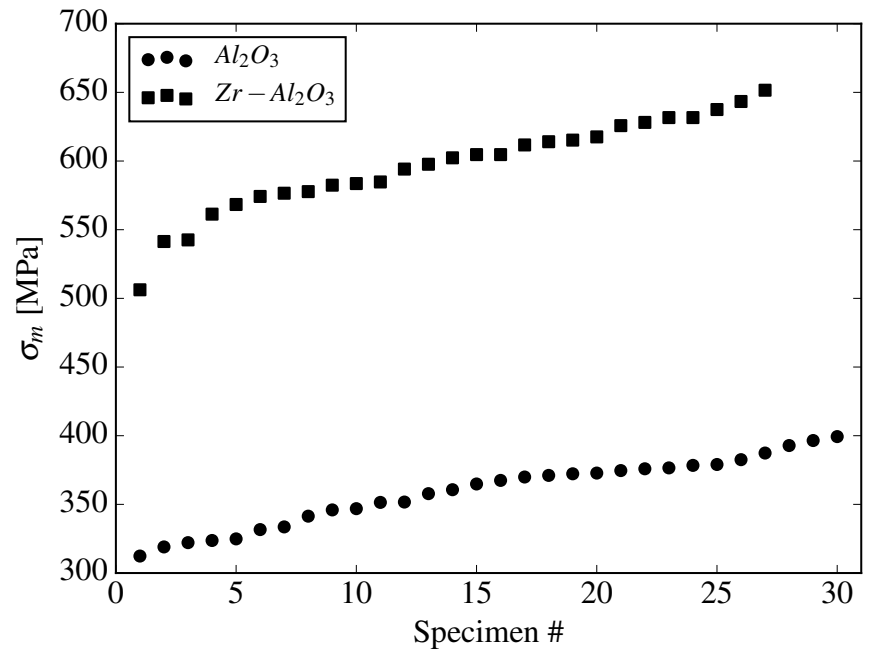

Figure 5: Sorting in ascending order of the specimens according to their breaking stress values, for both grades of ceramic.

3220) to prevent chipping. They are submitted to 3-point flexural test, on a Bose system equipped with a $220 \mathrm{~N}$ load cell, using a test fixture with $25 \mathrm{~mm}$ support span, traveling at $1 \mu \mathrm{m} / \mathrm{s}$.

The load/flexion measurements (not shown here) are linear up to the breaking point, which indicates the ceramics have an elastic-brittle behavior. Using this data, the Young's Modulus is derived from:

$$
E=\frac{F L^{3}}{48 \delta I_{z}}
$$

Where $\mathrm{F}$ is the maximum load, $\mathrm{L}$ the support span, $\delta$ the deflection, and $I_{z}=w t^{3} / 12(w$ and $t$ are the specimen width and thickness, respectively) is the moment of inertia around the $\mathrm{z}$-axis, which is normal to the bending plane. Figure 4 presents the Young's modulus value calculated for each specimen. From this graph, one can estimate the following values: $403 \pm 5 \mathrm{GPa}$ for $\mathrm{Al}_{2} \mathrm{O}_{3}$ and $330 \pm 10 \mathrm{GPa}$ for $\mathrm{Zr}-\mathrm{Al}_{2} \mathrm{O}_{3}$.

The Poisson's ratio (0.22) is derived from the average estimation between the Voigt and Reuss bounds for a ceramic poly- 


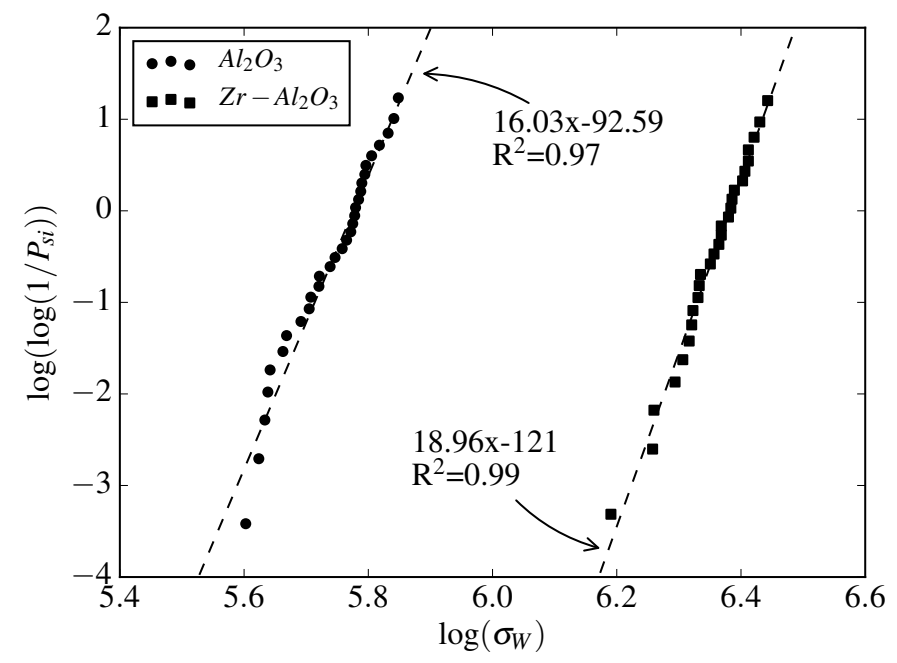

Figure 6: Probability of survival as a function of the Weibull stress for both grades of ceramic.

crystal, for which the single crystal elastic moduli are available [19], and approximated to have a cubic symmetry.

With a 3-point bending test configuration, the maximal stress (for rupture) is:

$$
\sigma_{m}=\frac{3 F L}{2 t^{2} w}
$$

The value of $\sigma_{m}$ measured for each sample is plotted in Fig. 5, in ascending order. The relatively low scattering in the experimental data demonstrates that the ceramic sheets have a homogeneous micro-structure.

\subsection{Weibull Analysis}

The Weibull analysis is adopted to describe the statistical rupture of ceramics. It considers the specimen as a series of elementary volumes. Each of these volumes has a statistical defect probability, and the rupture of the specimen is triggered by that of its weakest elementary volume.

The probability of rupture for the specimen can be written as:

$$
P_{R}=1-P_{S}\left(\sigma_{W}\right)=1-\exp \left[-\left(\frac{\sigma_{W}}{\sigma_{0}}\right)^{m}\right]
$$

with $P_{S}$ the probability of survival. The Weibull stress $\sigma_{W}=\sigma_{m}\left(\frac{V_{e f f}}{V_{0}}\right)^{\frac{1}{m}}$, where $m$ and $\sigma_{0}$ are the Weibull modulus and stress respectively and $V_{0}$ an elementary volume (here arbitrary set to $1 \mathrm{~mm}^{3}$ ).

From Fig. 5, the probability of survival for specimen $i$ (with $N$ the total specimen count for a given ceramic grade) is:

$$
P_{S i}=1-\left(\frac{i}{N+1}\right)
$$

From (3), $P_{S i}$ can also be written as:

$$
\log \left(\log \left(\frac{1}{P_{S i}}\right)\right)=m \log \sigma_{w i}-m \log \sigma_{0}
$$

Table 2: Properties identified for both grades of ceramic (assuming $V_{0}=$ $1 \mathrm{~mm}^{3}$ )

\begin{tabular}{cccccc} 
& $\begin{array}{c}\mathrm{E} \\
{[\mathrm{GPa}]}\end{array}$ & $v$ & $\mathrm{~m}$ & $\begin{array}{c}\sigma_{0} \\
{[\mathrm{MPa}]}\end{array}$ & $\begin{array}{c}V_{\text {eff }} \\
{\left[\mathrm{mm}^{3}\right]}\end{array}$ \\
\hline $\mathrm{Al}_{2} \mathrm{O}_{3}$ & 403 & 0,22 & 16.03 & 322 & 0.103 \\
$\mathrm{Zr}_{\mathrm{Al}} \mathrm{O}_{3}$ & 330 & 0.22 & 18.95 & 590 & 0.501 \\
\hline
\end{tabular}

To plot the graph in Fig. 6, one first considers $\sigma_{w i}=\sigma_{m i}$, and uses (4) to calculate $P_{S i}$. Some values of the Weibull parameters $m$ and $\sigma_{O}$ are then found. These values of $m$ and $\sigma_{0}$ are used in (5) to calculate the new value of $P_{S i}$. The process is iterated until convergence.

As a summary, the properties (elastic and rupture) of both grades of ceramic are listed in Table 2

\section{Characterization of the Metal/Ceramic Interface}

After the identification of the properties of both the copper and ceramic parts, the remaining step is to characterize their interface. This interface is described using a cohesive model, in which the Traction - Opening $(T-\delta)$ relationship mimics mechanically the failure process. The area under the traction-opening law corresponds to the separation energy, $\Phi_{\text {sep }}=\int^{\delta^{c r}} T d \delta$, with the nucleation of a crack for a characteristic opening $\delta^{c r}$. Debonding is triggered when the traction reaches a characteristic value $T_{\max }$ (traction at the onset of debonding). Therefore, given the Traction-Opening profile, two parameters need to be identified: $T_{\max }$ and $\Phi_{S e p}$ (separation energy). We present a methodology for this identification.

To identify these parameters, a two-level approach is used: we measure the force-displacement characteristic of a specimen during a four-point bending test, which is the "global" information. This information is supplemented by the in-situ measure of the crack advance. The latter "local" information is represented in a plot of crack advance vs. overall displacement. These measurements, at the global and local length scales, provide the data for the parameter identification of the cohesive model with an inverse methodology. In other words, the predictions of a Finite Elements (FE) model are compared to these measurements for the identification (at both scales) of the parameters $T_{\text {Max }}$ and $\Phi_{\text {Sep }}$.

\subsection{4-point Bending Test}

The tests presented in this section are performed on a Tinius-Olseb H10KS tensile tester, with a $5 \mathrm{kN}$ load cell, and a cross-head speed of $0.1 \mathrm{~mm} / \mathrm{s}$. The test fixture is connected to the tester by a ball-joint connection. The loading and support span are $25 \mathrm{~mm}$ and $50 \mathrm{~mm}$ respectively. In addition, a Prosilica GX6600 camera and a TC16M telecentric lens (Opto Engineering) are used for a high resolution (29 MPixels) observation of the crack propagation.

DBC specimens (Fig. 7a) are prepared as follows: starting with a DBC mastercard (Rogers-Curamik, $500 \mu \mathrm{m}$ copper on both sides, $250 \mu \mathrm{m} \mathrm{Zr}-\mathrm{Al}_{2} \mathrm{O}_{3}$ ), the copper patterns are 


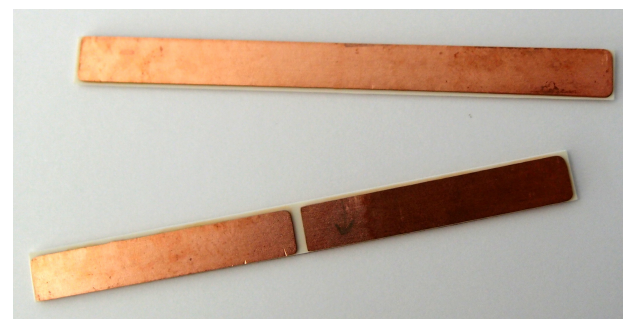

(a)

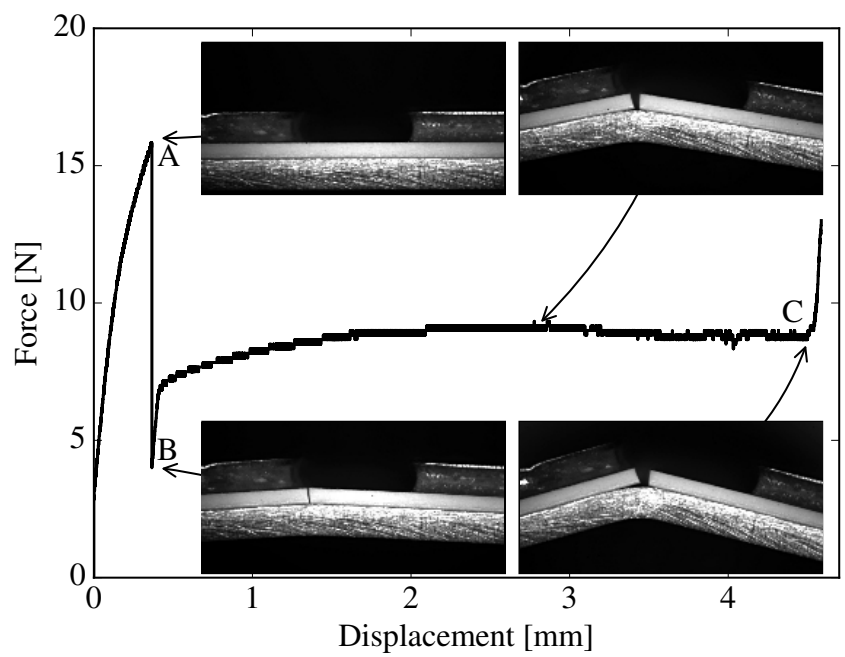

(b)

Figure 7: Copper-ceramic-copper $(500 \mu \mathrm{m}-250 \mu \mathrm{m}-500 \mu \mathrm{m})$ specimens (a), with one copper layer split ( $2 \mathrm{~mm}$ gap), and an example of a force/displacement characteristic measured with 4-point bending (b). Some of the photographs used for image correlation are presented, along with their corresponding position in the graph. They show a side view of the specimens, with the split copper layer on top.

formed using photosensitive resin, and chemically etched (ferric chloride) down to the ceramic layer. Individual specimens are then singulated using a wafer saw (Disco DAD3220). This ensures that minimum damage is introduced during the preparation. The final dimensions of the specimens are $80 \times 10 \mathrm{~mm}^{2}$.

\subsection{Experimental results}

An example of a force-displacement curve is presented in Fig. 7b, with some pictures of the corresponding specimen. Overall, 3 specimens were tested with consistent results. It can be described in 4 parts: The force vs. displacement curve increases up to point A, first linear elastically and then a decrease of the slope is observed prior to point $\mathrm{A}$ when the $\mathrm{Cu}$-layers start to deform plastically. Between points $\mathrm{A}$ and $\mathrm{B}$, the ceramic layer breaks, resulting in a large drop of the force, the test being displacement-controlled. When the ceramic fails, the test is stopped and restarted to adjust the optical set-up used to track the crack advance. From point $\mathrm{B}$ to point $\mathrm{C}$, an interfacial crack propagates between copper and ceramic (this is the part we will focus on). The test system reaches its limits after point $\mathrm{C}$, and the measurement is stopped.

Photographs of the specimen are taken during the 4-points bending test. These photographs are then analyzed with the

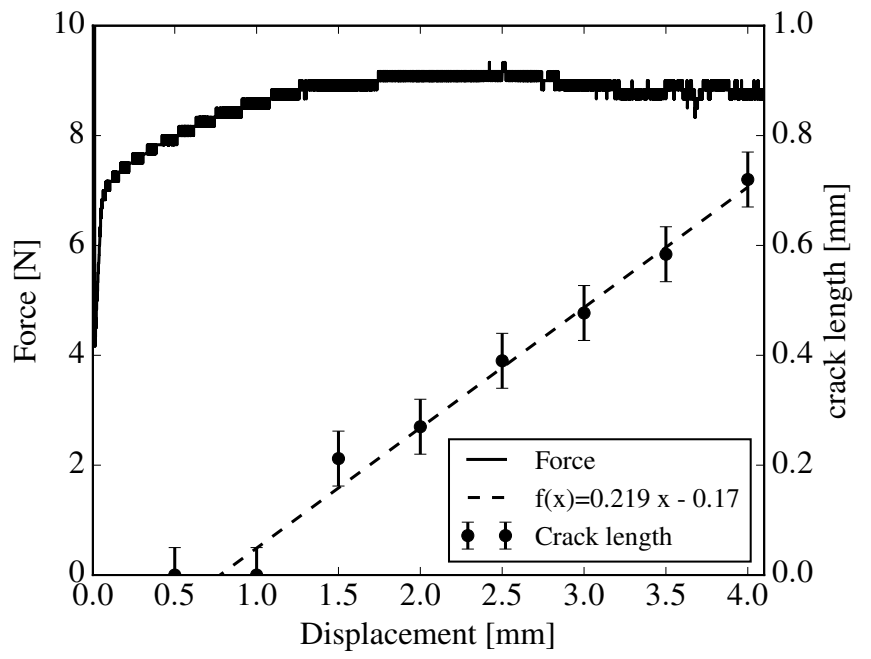

Figure 8: Force-displacement measurement (same data as in Fig. 7b, with a shift in the $\mathrm{x}$-axis so that point $\mathrm{B}$ corresponds to $\mathrm{x}=0$ ) and optical measurement of the interfacial crack length.

ImageJ software [20], to measure the crack length. By repeating the same measurement on a single image, the accuracy on the crack length measurement is estimated to be $\pm 50 \mu \mathrm{m}$. Such geometric measurements tend to under-estimate the total length of the crack, but our assumption is that the estimation error does not change as the crack propagates. In the identification, we will not consider the crack advance distance, but the rate of crack advance with the overall displacement, so that this uncertainty is not an issue. This measurement method is inspired from [21]. Fig. 8 presents the measurement results. The displacement scale is shifted so that 0 corresponds to point $\mathrm{B}$ in Fig. 7b. The rate of increase of the crack length with the displacement (slope of the dashed line) is the local information used for the cohesive model identification, the forcedisplacement curve (plain line) being the global information. Both are used for the identification of the cohesive model, which must satisfyingly predict the behaviour of the interface at the local and global scales. This is presented in the next section (4.4), in which a parameter set will be considered satisfying if it produces results which match on both the local and global scales.

\subsection{Cohesive model}

Hofinger et al. [22] proposed an analytical model for the energy release rate (or separation energy) in a 3-layer structure, with elastic linear behavior. Using the properties of the copper and ceramic layer identified in the previous sections, the thickness of the copper and ceramic layers $(0.5$ and $0.25 \mathrm{~mm}$ respectively), and the equations in [22], the separation energy is estimated at $\Phi_{S e p}=32 \mathrm{~J} / \mathrm{m}^{2}(0,032 \mathrm{~N} / \mathrm{mm})$. As a pure elastic behavior is assumed in this model, the resulting separation energy must be considered as a theoretical upper bound. The copper layer having an elasto-plastic behavior, it dissipates some of the external bending energy.

Many rupture models were proposed in the literature. One can mention the "eXtended Finite Elements Method" (X-FEM, 


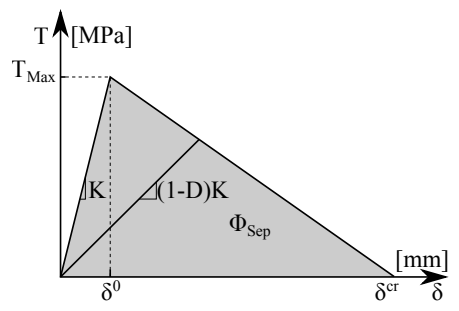

Figure 9: Traction law of a cohesive element: After $T_{\text {Max }}$, damage D occurs, resulting in a reduction in the apparent stiffness $\mathrm{K}$.
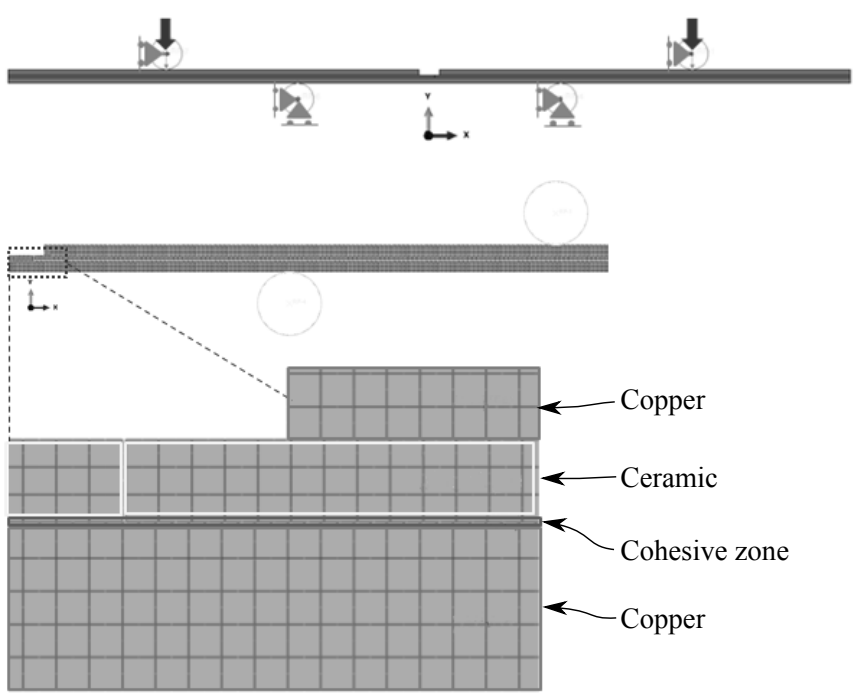

Figure 10: Finite Elements Model (Abaqus) of the 4-point flexural test. Cohesive elements were added between the ceramic and the bottom copper layers.

[23]), the "virtual crack model" [24] or the "cohesive model" [25]. We adopt a cohesive description as it incorporates an intrinsic length scale, $\delta^{c r}$ (Fig. 9), corresponding to the nucleation of a crack locally. This description enables the investigation of size effects and, in the present case, of thickness effects. A cohesive model mimics the mechanical response of an interface in a traction-separation law. The formulation implemented in Abaqus is used and depicted schematically in Fig. 9. When the interface is subjected to a mechanical load, its traction increases up to $T_{\text {Max }}$, the latter corresponding to the onset of debonding. Initially, the stiffness is "large enough" to ensure the continuity of the displacement field. During the debonding, the traction decays down to zero at the opening $\delta^{c r}$. This is implemented within a framework similar to damage mechanics with a damage variable $D, D=0$ prior to $T=T_{\text {Max }}, 0<D<1$ during debonding and $D=1$ when failure occurs. Thus, the interface energy is

$$
\Phi_{S e p}=\frac{1}{2} T_{M a x} \delta^{c r}
$$

Details of the implementations can be found in [25].

The cohesive elements are implemented in the FEM model as shown in Fig. 10 with a 2-D model of the 4-point bending test. The test fixture is represented using rigid $3 \mathrm{~mm}$-diameter rolls. As presented above, a plastic-elastic model is used for the copper and a linear-elastic model for the ceramic. The corre-

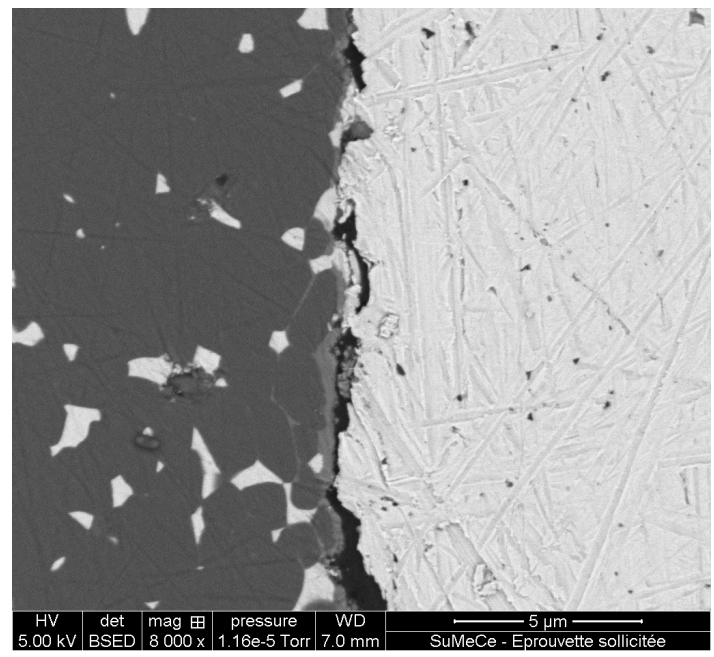

(a)

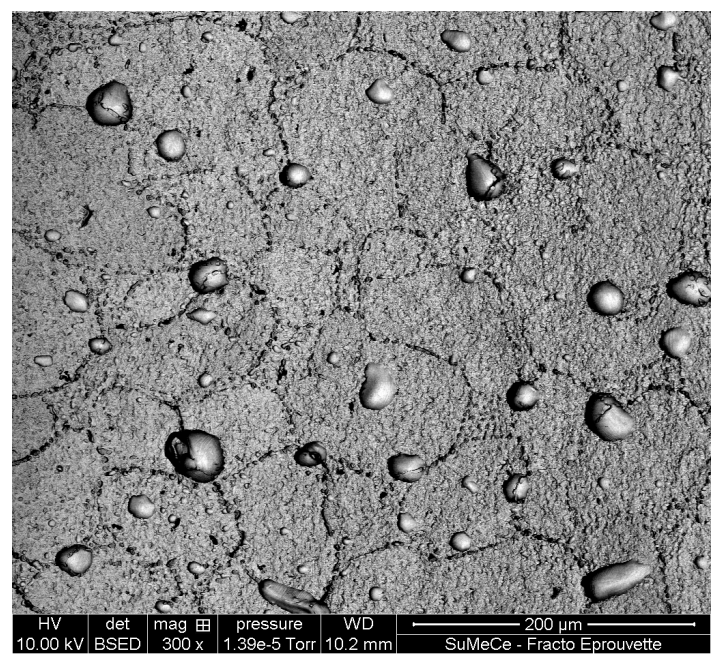

(b)

Figure 11: Scanning Electron Microscope (SEM) images of (a) a cross section of a cracked specimen (the ceramic is on the left, the copper on the right) and (b) surface of the delaminated copper showing that there is no trace of alumina remaining (this was confirmed by an elemental analysis not shown here). Also, the copper surface shows "bubbles" corresponding to defects in the DBC assembly.

sponding parameters are presented in tables 1 and 2. Ceramic and copper are meshed with $100 \times 100 \mu \mathrm{m}^{2}$ elements, while the interface between the ceramic and the bottom copper layer receives $50 \times 50 \mu \mathrm{m}^{2}$ cohesive elements (described using a damage variable named "SDEG" in Abaqus).

The hypothesis of a rupture localized exactly at the ceramiccopper interface (as opposed to a crack propagating in the ceramic, near to the interface) is confirmed by the cross section shown in Fig. 11a. The SEM image of the copper layer after rupture (Fig. 11b) also shows that there is no alumina remaining. It also shows a number of small $(\approx 20 \mu \mathrm{m}$ in diameter $)$ defects. These defects will also be considered in the FEM model, for the parameter identification. 


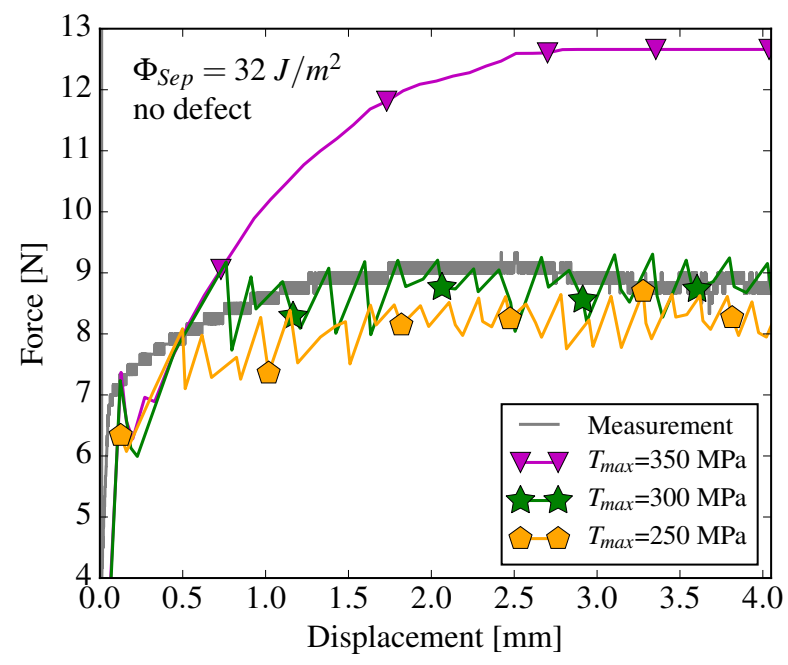

(a)

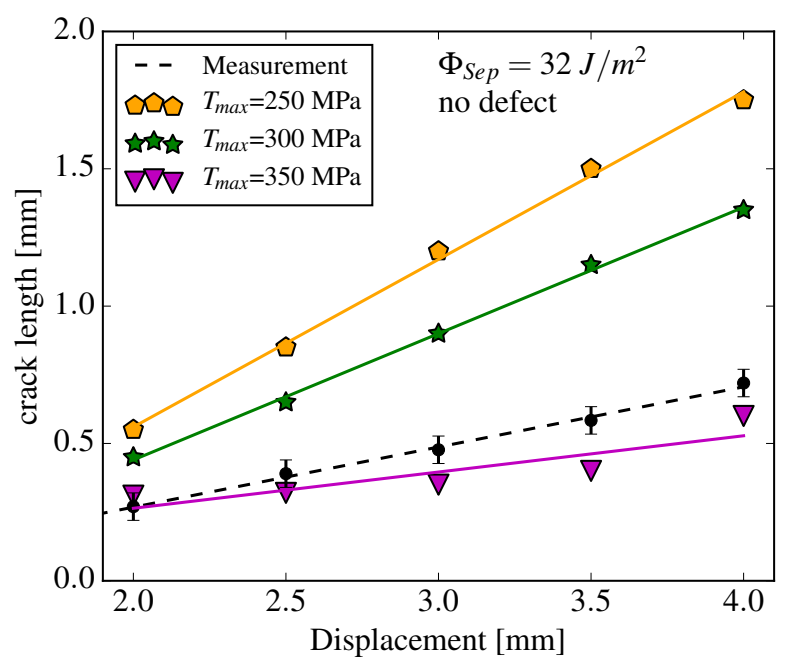

(b)

Figure 12: Effect of the $T_{\text {Max }}$ parameters on the simulation results, for $\Phi_{\text {Sep }}=32 \mathrm{~J} / \mathrm{m}^{2}$, compared to the (a) force displacement and (b) crack length measurements. The experimental data corresponds to that in Fig. 8.

\subsection{Parameter identification for the cohesive model}

In this section, we compare the predictions of FE simulations of the 4-point bending test (for different parameter values) with the experimental data from Fig. 8. Starting with a $\Phi_{S e p}$ value equal to $32 \mathrm{~J} / \mathrm{m}^{2}$, which corresponds to an upper bound, as explained in section 4.3, simulations are run for different values of $T_{\text {Max }}$ (using the model in Fig. 10). The predictions at both scales are then compared to the measurements presented in Fig. 8. This is initiated with $\Phi_{S e p}=32 \mathrm{~J} / \mathrm{m}$, and the $\Phi_{S e p}$ value is gradualy reduced until the model satisfyingly captures both measurements: force vs. displacement as well as the slope of the crack length advance vs. displacement.

Fig. 12 presents the simulation results for $\Phi_{\text {Sep }}=$ $32 \mathrm{~J} / \mathrm{m}^{2}$, with $T_{M a x}$ values ranging from 250 to $350 \mathrm{MPa}$. The force-displacement data is shown in fig. 12a, and the crack length/displacement data (restricted to the linear part of the curve) in Fig. 12b. No $T_{\text {Max }}$ value could simultaneously cap-

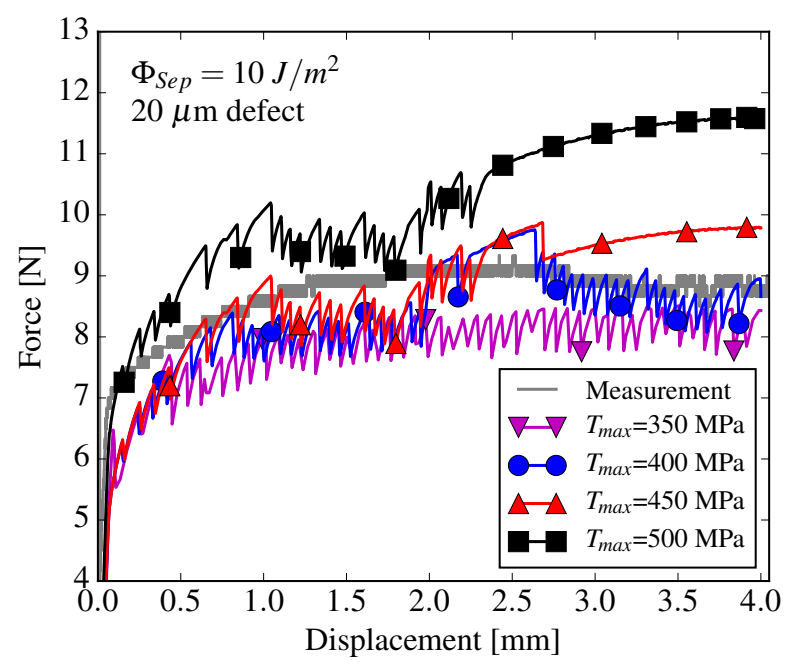

(a)

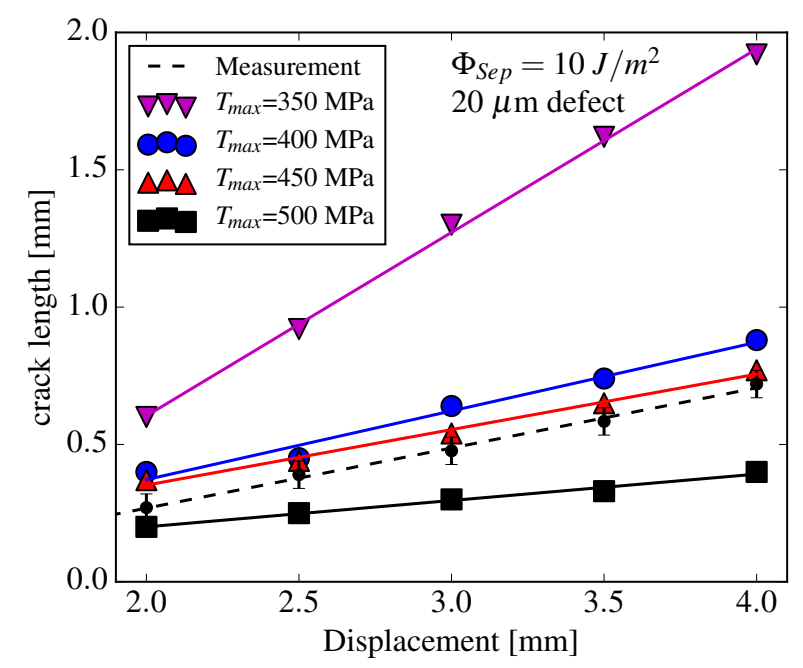

(b)

Figure 13: Effect of the $T_{\text {Max }}$ parameters on the simulation results, for $\Phi_{S e p}=10 \mathrm{~J} / \mathrm{m}^{2}$, compared to the (a) force displacement and (b) crack length measurements. The experimental data corresponds to that in Fig. 8.

ture both experimental datasets: for example, while $T_{\text {Max }}=$ $300 \mathrm{MPa}$ seems adequate in Fig. 12a (i.e at the global scale), it is not in Fig. 12b (local scale).

The same procedure was repeated for decreasing $\Phi_{S e p}$ values, down to $5 \mathrm{~N} / \mathrm{m}^{2}$, but whatever $\Phi_{S e p}$, no satisfying $T_{M a x}$ value could be found. A possible deviation of the crack along the interface after the ceramic breakdown was then considered. A second series of simulations was run, for the same $\Phi_{S e p}$ range, but now including an initial $20 \mu \mathrm{m}$ defect at the edge of the copper-ceramic interface (longer defects have no influence on the predictions). This model represents the defects observed in Fig. 11 b.

One example of the second series of simulations is given in Fig. 13, for $\Phi_{S e p}=10 \mathrm{~J} / \mathrm{m}^{2}$. It can be seen that $T_{\text {Max }}=400$ and $450 \mathrm{MPa}$ offer a satisfying and simultaneous match for both the force/displacement (Fig. 13a) and the crack length/displacement (Fig. 13b) data. 

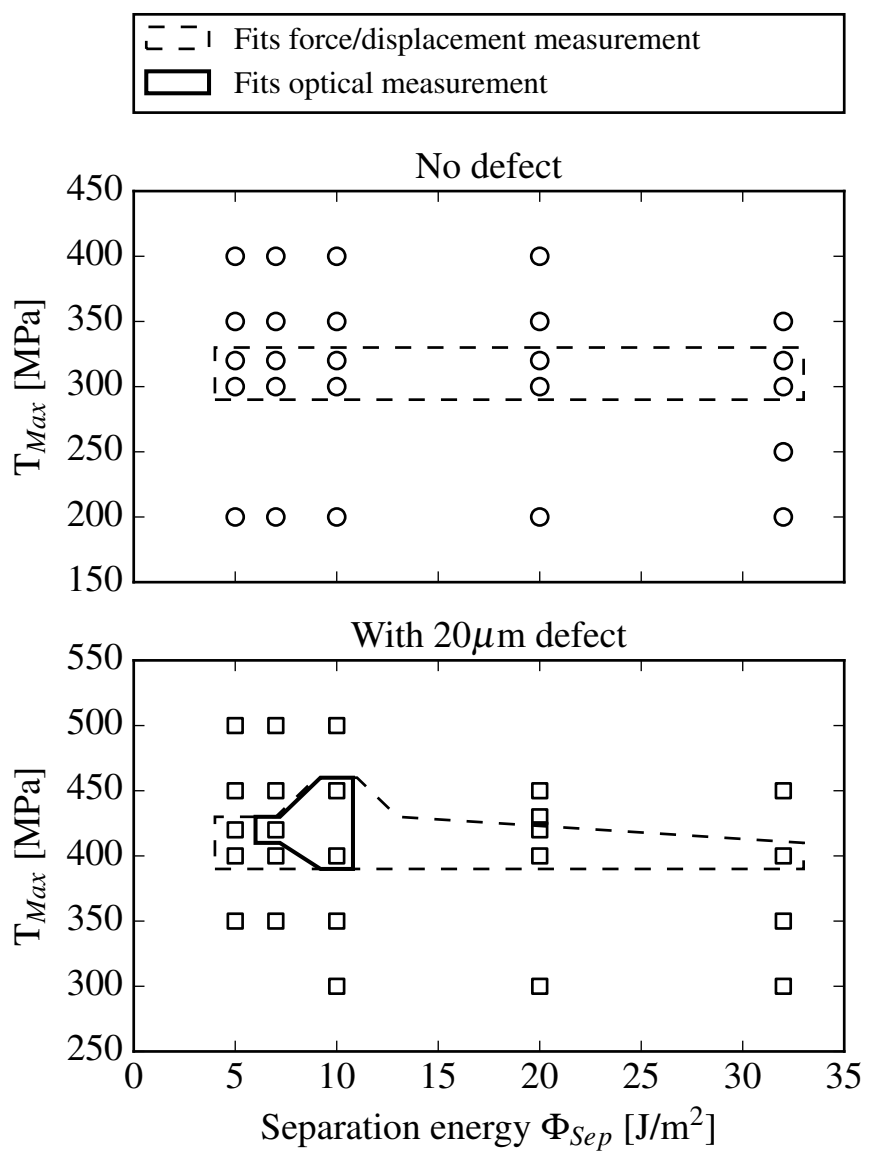

Figure 14: Overview of the modeling results in the $\left(\Phi_{S e p}, T_{M a x}\right)$ domain, for models without and with a $20 \mu \mathrm{m}$ defect. The simulations which fits with the force-displacement measurements are in the dashed box. Those which fit with the optical measurements are in the plain box. Only a few parameter sets fits both

An overview of the parameter sets evaluated is given in Fig. 14, for a model without any defect (top) and for a model with a $20 \mu \mathrm{m}$ defect introduced a the interface. It shows that while a satisfying match can be found for the force/displacement measurements in both cases (with and without defect), over a large range of $\Phi_{\text {Sep }}$ values, the optical measurement is much more demanding. Only three parameter sets give a realistic evolution of the crack length: $\left(\Phi_{\text {Sep }}\right.$, $\left.T_{\text {Max }}\right)=\left(7 \mathrm{~J} / \mathrm{m}^{2}, 420 \mathrm{MPa}\right),\left(10 \mathrm{~J} / \mathrm{m}^{2}, 400 \mathrm{MPa}\right)$ and $\left(10 \mathrm{~J} / \mathrm{m}^{2}\right.$, $450 \mathrm{MPa})$. These $\left(\Phi_{S e p}, T_{\text {Max }}\right)$ pairs correspond to the identification of the cohesive parameters.

\section{Discussion and conclusion}

\subsection{Elastic-plastic behavior of copper}

The results presented here show that the DBC assembly has a fundamental effect on the copper behavior. After annealing at high temperature, and to some extend after cooling down under mechanical constraint, the copper layers exhibit a much lower plastic yield stress. A method was presented in this paper to produce representative tensile test specimens: removal of the ceramic in a DBC assembly by chemical means, followed by electro-erosion machining to prevent stress build-up.

In repetitive mechanical stress, the annealed copper layer shows a cinematic hardening. In consequence, a non-linear hardening model (Armstrong-Frederick) was used.

\subsection{Brittle rupture of the ceramic layer}

3 -point flexural tests on two ceramic variants shows a very good quality of the material and of the specimen preparation process: there is little experimental scattering (less than $20 \%$ variation in rupture stress). A classical weibull analysis is performed to identify the parameters of the elastic-brittle rupture model.

\subsection{Modeling of the copper-ceramic interface}

A 4-point flexural test configuration was used, and demonstrates that once the ceramic layer has cracked, the crack deviates along the metal-ceramic interface. This is confirmed by SEM observations, which show that there are no ceramic residues remaining on the copper layer. In addition to the standard force/displacement measurements during the flexural test, the crack length is captured using an optical system.

An analytical model (considering a 3-layer specimen with an elastic behavior) is used to calculate a separation energy value. Because of its plastic behavior, the copper layer dissipates a large part of the energy supplied to the specimen. Therefore, the calculated separation energy value $\left(\Phi_{\text {Sep }}=32 \mathrm{~J} / \mathrm{m}^{2}\right)$ is used as an upper bound.

To simulate the progressive separation of the ceramic and the copper, we used a cohesive model for the response of the interface.

The identification of the two parameters of the cohesive model $\left(\Phi_{\text {Sep }}\right.$ and $T_{\text {Max }}$ ) is derived from information at two scales: force vs. displacement and crack length vs. displacement measurements. Indeed, while the identification of $T_{M a x}$ is fairly straightforward using the force vs. displacement data alone, this data does not allow to discriminate between $\Phi_{S e p}$ values. On the contrary, once a good estimate of $T_{\text {Max }}$ has been found, a more accurate $\Phi_{\text {Sep }}$ value can be identified using the crack length vs displacement measurement.

\section{Conclusion}

Modeling of the damage induced by thermo-mechanical cycling in DBC requires a proper characterization of all constituents of the DBC. This article details the steps necessary for this characterization. First elasto-plastic behavior of the copper layer is evaluated on a copper sheet submitted to the same thermo-mechanical treatments as on a DBC, Then fracture properties and Young's modulus of the ceramic layer are measured. Finally, the interfacial crack propagation is characterized and, coupled with FE modeling with cohesive zones, provides information on the cohesive zone parameters.

It was found that only three very close sets of parameters among the 25 tested could satisfactorily reproduce both the 
load-displacement and crack length-displacement curves observed during experimental 4-points bending tests of the DBC specimens specially devised for this study.

This makes it possible to simulate the damages induced by thermomechanical cycling, in DBCs, which will be the subject of a next paper.

\section{Acknowledgment}

The authors would like to thank Rogers-Curamik for their assistance and the materials they provided for this study. This work was funded by the Institut Carnot I@L, under the grant name SuMeCe.

\section{References}

[1] W. W. Sheng, R. P. Colino, Power Electronic Modules: Design and Manufacture, 1st Edition, CRC, 2004.

[2] J. F. Burgess, C. A. Neugebauer, Direct bonding of metals with a metalgas eutectic, US Patent 3,744,120 (Jul. 10 1973).

[3] C. Beraud, M. Courbiere, C. Esnouf, D. Juve, D. Treheux, Study of copper-alumina bonding, Journal of Materials Science 24 (12) (1989) 4545-4554. doi:10.1007/BF00544543.

[4] J. Burgess, C. Neugebauer, G. Flanagan, R. Moore, The direct bonding of metals to ceramics and application in electronics, Active and Passive Electronic Components 2 (4) (1976) 233-240.

[5] J. Jarrige, T. Joyeux, J. Lecompte, J. Labbe, Influence of oxygen on the joining between copper and aluminium nitride, Journal of the European Ceramic Society 27 (1) (2007) 337-341. doi:10.1016/j.jeurceramsoc.2006.02.028.

[6] J. Schulz-Harder, Advantages and new development of direct bonded copper substrates, Microelectronics Reliability 43 (3) (2003) 359-365. doi:10.1016/S0026-2714(02)00343-8.

[7] J. Lutz, H. Schlangenotto, U. Scheuermann, R. De Donker, Semiconductor Power Devices - Physics, Characteristics, Reliability, Springer, 2011.

[8] A. Schletz, M. Nomann, M. Rauch, S. Kraft, S. Egelkraut, Reliability of Insulating Substrates - High Temperature Power Electronics for More Electric Aircraft, in: Proceedings of the European Power Electronics Conference, Birmingham, UK, 2011, p. 7p.

[9] C. Buttay, D. Planson, B. Allard, D. Bergogne, P. Bevilacqua, C. Joubert, M. Lazar, C. Martin, H. Morel, D. Tournier, C. Raynaud, State of the art of high temperature power electronics, Materials Science and Engineering: B 176 (4) (2011) 283-288, microtechnology and Thermal Problems in Electronics. doi:10.1016/j.mseb.2010.10.003.

[10] S. Yang, A. Bryant, P. Mawby, D. Xiang, L. Ran, P. Tavner, An IndustryBased Survey of Reliability in Power Electronic Converters, IEEE transactions on industry applications 47 (3) (2011) 1441-1451.

[11] L. Dupont, Z. Khatir, S. Lefebvre, S. Bontemps, Effects of metallization thickness of ceramic substrates on the reliability of power assemblies under high temperature cycling, Microelectronics Reliability 46 (9) (2006) 1766 - 1771. doi:10.1016/j.microrel.2006.07.057.

[12] J.-D. Mathias, G. Pierre-Marie, S. Jean-Franois, Architectural optimization for microelectronic packaging, Applied Thermal Engineering, 2009.

[13] L. Xu, M. Wang, Y. Zhou, Z. Qian, S. Liu, An optimal structural design to improve the reliability of $\mathrm{Al} 2 \mathrm{O} 3-\mathrm{DBC}$ substrates under thermal cycling, Microelectronics Reliability 56 (2016) 101-108.

[14] S. Pietranico, P. S., S. Lefebvre, Z. Khatir, S. Bontemps, Characterisation of power modules ceramic substrates for reliability aspects, Microelectronics Reliability (49) (2009) 1260-1266. doi:10.1016/j.microrel.2009.06.026.

[15] S. Pietranico, S. Pommier, S. Lefebvre, S. Pattofatto, Thermal fatigue and failure of electronic power device substrates, International Journal of Fatigue 31 (11) (2009) 1911-1920.

[16] Curamik, curamik Ceramic Substrates DBC technology - Design Rules, Tech. rep., Rogers Curamik (dec 2014).
[17] H. Leclerc, J.-N. Périé, S. Roux, F. Hild, Integrated digital image correlation for the identification of mechanical properties, in: International Conference on Computer Vision/Computer Graphics Collaboration Techniques and Applications, Springer, 2009, pp. 161-171.

[18] J. Lemaitre, J.-L. Chaboche, J. Lemaitre, Mechanics of Solid Materials, Cambridge Univ Pr., 2002.

[19] T. J. Ahrens, Mineral physics and crystallography: a handbook of physical constants, American Geophysical Union, 1995.

[20] W. Rasband, ImageJ (1997-2016). URL http://imagej.nih.gov/ij/

[21] B. Blaysat, J. P. Hoefnagels, G. Lubineau, M. Alfano, M. G. Geers, Interface debonding characterization by image correlation integrated with double cantilever beam kinematics, International Journal of Solids and Structures 55 (2015) 79-91.

[22] I. Hofinger, M. Oechsner, H.-A. Bahr, M. V. Swain, Modified four-point bending specimen for determining the interface fracture energy for thin, brittle layers, International Journal of Fracture 92 (3) (1998) 213-220.

[23] N. Moës, A. Gravouil, T. Belytschko, Non-planar 3D crack growth by the extended finite element and level setsPart I: Mechanical model, International Journal for Numerical Methods in Engineering 53 (11) (2002) 2549-2568.

[24] D. M. Parks, A stiffness derivative finite element technique for determination of crack tip stress intensity factors, International Journal of Fracture 10 (4) (1974) 487-502.

[25] P. P. Camanho, C. G. Dávila, Mixed-mode decohesion finite elements for the simulation of delamination in composite materials, Tech. rep., NASA (2002). 